Caligrama, Belo Horizonte, v. 22, n. 2, p. 5-31, 2017

\title{
Vogais médias pretônicas: falares mineiros
}

\section{Pretonic mid vowels: Minas Gerais dialects}

\author{
Melina Rezende Dias \\ Instituto Federal Fluminense, Santo Antônio de Pádua, Rio de Janeiro / Brasil \\ melinarezende@yahoo.com.br \\ Maria do Carmo Viegas \\ Universidade Federal de Minas Gerais, Belo Horizonte, Minas Gerais / Brasil \\ mariadocarmo.viegas@gmail.com
}

Resumo: Na divisão dos falares proposta por Zágari (1998), Machacalis estaria na área do falar baiano, Piranga e Ouro Branco no falar mineiro. Já na divisão proposta por Nascentes (1953), Machacalis estaria na área de falar baiano, Piranga, no falar fluminense e Ouro Branco no falar mineiro. A realização das pretônicas é característica relevante para as diversas divisões dos falares brasileiros. Assim, este trabalho estuda a variação das vogais médias pretônicas nos referidos municípios. Os objetivos deste artigo são: descrever as vogais médias pretônicas de alguns falares mineiros e assim contribuir para a descrição das variedades de Minas Gerais e do português brasileiro (PB), estudar os processos fonológicos pelos quais passam essas vogais nas três cidades, determinar quais são os gatilhos desses processos e discutir as propostas de divisão dos falares mineiros em que se encaixam as comunidades em questão. Adotouse o modelo teórico-metodológico da Teoria da Variação e Mudança Linguística (LABOV, 1972) e o modelo da Fonologia Autossegmental (GOLDSMITH, 1976) e da Geometria de Traços (CLEMENTS; HUME, 1996). Para o tratamento estatístico, foi utilizado o modelo de regressão logística, presente no software SPSS. Averiguaram-se quais foram os 
grupos de fatores linguísticos e os grupos de fatores sociais atuantes no alçamento e na abertura da vogal média pretônica.

Palavras-chave: variação das vogais médias pretônicas; alçamento; abertura; fonologia autossegmental; falares mineiros.

Abstract: In Zagari (1998), the city of Machacalis is Baiano speaking area, while the city of Piranga and the city of Ouro Branco are Mineiro area. Nascentes (1953) proposed Machacalis as Baiano speaking area, Piranga as Fluminense area and Ouro Branco as Mineiro area. The productions of pretonic vowels is relevant to the various divisions of Brazilian speech. Thus, this work studies the variation of the pretonic vowels in Minas Gerais' towns of Piranga, Ouro Branco and Machacalis. This research goals are: to describe the pretonic vowels contributing to a description of Minas Gerais and the Brazilian Portuguese speaking varieties; to study the phonological processes involved to determine the triggers of these processes and to discuss the proposed division of Minas Gerais local dialects. The theoretical-methodological model of Linguistic Variation and Change (LABOV, 1972) and the Autossegmental Phonology (GOLDSMITH, 1976) and Feature Geometry (CLEMENTS; HUME, 1996) models were adopted. For statistical analysis, the logistic regression model presented in SPSS software was used. We have investigated the social and internal factors involved.

Keywords: variation of the pretonic vowels; raising production; halfopen production; autossegmental phonology; Minas Gerais local dialects.

Recebido em: 2 de março de 2017. Aprovado em: 10 de agosto de 2017.

Neste texto apresentamos um estudo da variação das vogais médias pretônicas em três cidades mineiras: Ouro Branco, Piranga e Machacalis. Essas cidades pertencem a áreas dialetais diferentes, conforme Nascentes (1953): Piranga poderia ser enquadrada na área de falar fluminense; Ouro Branco na área de falar mineiro; e Machacalis na área de falar baiano. Interessa-nos responder, principalmente, às seguintes perguntas: 
A) Quais são os processos fonético-fonológicos envolvidos?

B) Há diferenças significativas entre as cidades pesquisadas?

\section{Métodos e técnicas ${ }^{1}$}

Descrevemos e analisamos os dados de acordo com os princípios metodológicos da Teoria da Variação e Mudança Linguística, ou Sociolinguística Variacionista, proposta por Labov (1972). A pesquisa sociolinguística implica o levantamento criterioso dos registros de língua falada, descrevendo a variável (conjunto de variantes) e traçando um perfil das variantes (formas diferentes que têm o mesmo valor de verdade em um mesmo contexto); a análise dos fatores estruturais e sociais favorecedores; o encaixamento da variável no sistema linguístico e social da comunidade; a avaliação da variável; e a explicação de como se deu a implementação de determinada forma variante. Nossa análise apoia-se na Teoria da Variação e Mudança Linguística tanto porque consideramos adequado dar um tratamento quantitativo aos dados, observando quais são os fatores estatisticamente relevantes na explicação do fenômeno, quanto porque o aparato teórico da Sociolinguística Variacionista permite lidar com o componente social que contribui para influenciar a variação e a mudança linguística.

Utilizamo-nos também da Fonologia Autossegmental (GOLDSMITH, 1976) e da Geometria de Traços (CLEMENTS; HUME, 1996) para a análise dos dados.

Goldsmith, em sua tese de doutorado, em 1976, apresentou uma teoria para tratar dos fenômenos tonais. O autor propôs que as representações fonológicas e fonéticas não consistiam numa única cadeia de segmentos. Explicou que existem formas subjacentes e de superfície que consistem em cadeias de segmentos paralelos dispostas em dois ou mais níveis. Então, propôs que as representações fonológicas se constituem de diversos níveis paralelos e que há uma hierarquia entre os traços que integram a estrutura interna dos segmentos. Dessa forma, os segmentos são analisados em camadas ou tiers. Assim, os sons são divididos em partes tomadas independentemente.

\footnotetext{
${ }^{1}$ Esta pesquisa foi aprovada pelo Comitê de Ética em Pesquisa da UFMG - COEP. Protocolo de aprovação no: 0350.0.203.000-11.
} 
Clements e Hume (1996, p. 4) explicam: "In this approach, segments are represented in terms of hierarchically-organized node configurations whose terminal nodes are feature values, and whose intermediate nodes represent constituents." ${ }^{\prime 2}$

Os autores fazem a representação dos traços numa estrutura arbórea:

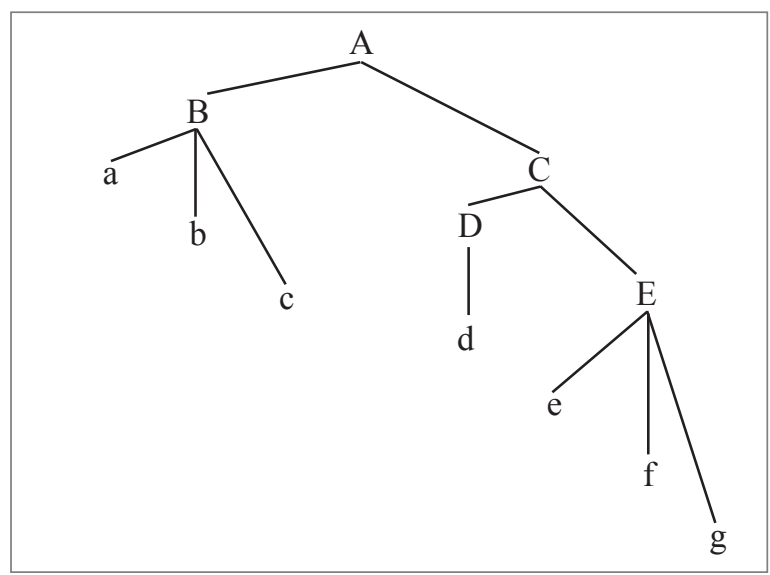

Fonte: Clements; Hume, 1996, p. 4.

\section{Matzenauer esclarece:}

A estrutura arbórea que representa a geometria de traços possibilita expressar a naturalidade dos processos fonológicos que ocorrem nas línguas do mundo, atendendo sempre ao princípio referido [...], isto é, tem de mostrar que constituem uma única operação, seja de desligamento de uma linha de associação ou de espraiamento de um traço. Em consequência, a estrutura apresenta, sob o mesmo nó de classe, traços que funcionam solidariamente em processos fonológicos. Isso quer dizer que essa estrutura encontra evidência no funcionamento da fonologia das línguas: a existência de cada nó de classe e a subordinação de traços na estrutura não é aleatória, ou seja, os nós têm razão de existir quando há comprovação de

\footnotetext{
${ }^{2}$ Matzenauer (2010) traduz essa explicação de Clements e Hume como: nós terminais são traços fonológicos e nós intermediários são classes de traços. Seguindo essa tradução temos: "Nesta abordagem, os segmentos são representados em configurações de nós, organizados hierarquicamente, cujos nós terminais são traços fonológicos e cujos nós intermediários são classes de traços" (tradução nossa).
} 
que os traços que estão sob o seu domínio funcionam como uma unidade em regras fonológicas. (MATZENAUER, 2010, p. 52)

Os dados foram coletados em entrevistas gravadas que compõem o corpus VARFON-Minas. O corpus aqui utilizado foi constituído com dados da fala de 24 informantes que foram selecionados considerando os fatores sociais: origem, sexo e faixa etária. Como pode ser visto na tabela seguinte:

TABELA 1 - Informantes e faixa etária

\begin{tabular}{|c|c|c|c|c|c|}
\hline \multicolumn{2}{|r|}{ Ouro Branco } & \multicolumn{2}{|r|}{ Piranga } & \multicolumn{2}{|r|}{ Machacalis } \\
\hline $\begin{array}{c}18 \text { a } 24 \\
\text { anos }\end{array}$ & $\begin{array}{l}2 \text { informantes masculinos } \\
2 \text { informantes femininos }\end{array}$ & $\begin{array}{c}18 \text { a } 24 \\
\text { Anos }\end{array}$ & $\begin{array}{l}2 \text { informantes masculinos } \\
2 \text { informantes femininos }\end{array}$ & $\begin{array}{c}18 \text { a } 24 \\
\text { anos }\end{array}$ & $\begin{array}{l}2 \text { informantes masculinos } \\
2 \text { informantes femininos }\end{array}$ \\
\hline $\begin{array}{c}40 \text { a } 60 \\
\text { anos }\end{array}$ & $\begin{array}{l}2 \text { informantes masculinos } \\
2 \text { informantes femininos }\end{array}$ & $\begin{array}{c}40 \text { a } 60 \\
\text { Anos }\end{array}$ & $\begin{array}{l}2 \text { informantes masculinos } \\
2 \text { informantes femininos }\end{array}$ & $\begin{array}{c}40 \text { a } 60 \\
\text { anos }\end{array}$ & $\begin{array}{l}2 \text { informantes masculinos } \\
2 \text { informantes femininos }\end{array}$ \\
\hline Total & 8 informantes & Total & 8 informantes & Total & 8 informantes \\
\hline
\end{tabular}

Foi realizado ainda o controle de variáveis não pesquisadas como: grupo social e escolaridade. Assim, todos os informantes pertenciam ao grupo social intermediário e possuíam ensino médio completo.

Três variantes de cada uma das duas variáveis (e) e (o) foram analisadas. Assim, temos, neste estudo, seis variantes:

$$
\begin{aligned}
& \text { (e) }-[\mathrm{e}] ;[\varepsilon] ;[\mathrm{i}] \\
& \text { (o) }-[\mathrm{o}] ;[\mathrm{o}] ;[\mathrm{u}]
\end{aligned}
$$

Fizemos a análise de (e) e (o) separadamente.

Analisamos a variação $[\mathrm{e} \sim \mathrm{i}],[\tilde{\mathrm{e}} \sim \tilde{1}],[\mathrm{o} \sim \mathrm{u}],[\tilde{\mathrm{o}} \sim \tilde{\mathrm{u}}]-$ alçamento $^{3}-$ e a variação $[\mathrm{e} \sim \varepsilon],[\mathrm{o} \sim 0]$ - abertura. Para tal, utilizamos principalmente modelos de regressão logística, dentre outras ferramentas estatísticas do conjunto de softwares SPSS.

Para maior controle dos dados, alguns contextos foram separados para fins desta análise. Separamos antes de fazer a regressão: início de palavra e encontros vocálicos. Inserimos na regressão apenas as vogais

\footnotetext{
${ }^{3}$ Utilizamos o termo alçamento por estar consagrado na literatura.
} 
com distância 1 da sílaba tônica e apenas aquelas do radical. Separamos alguns itens lexicais, principalmente os não variáveis na amostragem.

Levantamos na literatura vários grupos de fatores que poderiam influenciar os processos. Fizemos o cruzamento entre cada variável dependente e cada variável independente e separamos os fatores que não tiveram ocorrência de uma das variáveis dependentes, ou seja, os fatores com realização categórica da vogal.

Ao final, os grupos de fatores inseridos na regressão para o alçamento foram: vogal da sílaba tônica, modo do segmento seguinte, classe gramatical, distância do início da palavra, sexo, faixa etária (ou agrupamento social quando houve interação entre sexo e faixa etária). Para a abertura, inserimos os mesmos grupos de fatores e acrescentamos o grupo de fator paradigma com vogal aberta.

Todos os dados e procedimentos estão descritos detalhadamente em Dias (2014).

\section{Descrição e análise} análises:

Vejamos o resumo do que ocorre em cada cidade após todas as

QUADRO 1 - Fatores favorecedores do alçamento e da abertura de /e/ em Ouro Branco

\begin{tabular}{|l|c|c|}
\hline \multicolumn{1}{|c|}{ Fator } & $\begin{array}{c}\text { Ouro Branco } \\
\text { Alçamento de /e/ }\end{array}$ & $\begin{array}{c}\text { Ouro Branco } \\
\text { Abertura de /e/ }\end{array}$ \\
\hline Vogal tônica & HV [-aberto2] & HV [+aberto3] \\
\hline Modo seguinte & {$[$-contínuo] } & \\
\hline Classe gramatical & Verbos & Nomes \\
\hline Paradigma & & \multirow{2}{*}{ Fem./adulto } \\
\hline Sexo & & \\
\hline Faixa etária & jovens & \\
\hline
\end{tabular}


QUADRO 2 - Fatores favorecedores do alçamento e da abertura de /e/ em Piranga

\begin{tabular}{|l|c|c|}
\hline \multicolumn{1}{|c|}{ Fator } & $\begin{array}{c}\text { Piranga } \\
\text { Alçamento de /e/ }\end{array}$ & $\begin{array}{c}\text { Piranga } \\
\text { Abertura de /e/ }\end{array}$ \\
\hline Vogal tônica & HV [-aberto2] & HV [+aberto3] \\
\hline Modo seguinte & [-contínuo -nasal] & \\
\hline Classe gramatical & & paradigma com vogal aberta \\
\hline Paradigma & & masculino \\
\hline Sexo & & \\
\hline Faixa etária & & \\
\hline
\end{tabular}

QUADRO 3 - Fatores favorecedores do alçamento e da abertura de /o/ em Ouro Branco

\begin{tabular}{|l|c|c|}
\hline \multicolumn{1}{|c|}{ Fator } & $\begin{array}{c}\text { Ouro Branco } \\
\text { Alçamento de /o/ }\end{array}$ & $\begin{array}{c}\text { Ouro Branco } \\
\text { Abertura de /o/ }\end{array}$ \\
\hline Modo tônica & HV [-aberto2] & HV [+aberto3] \\
\hline Classe gramatical & [-soante + contínuo] & \\
\hline Paradigma & & paradigma com vogal aberta \\
\hline Sexo & & $\begin{array}{c}\text { feminino/adulto } \\
\text { masculino/jovem }\end{array}$ \\
\hline Faixa etária & & \\
\hline
\end{tabular}

QUADRO 4 - Fatores favorecedores do alçamento e da abertura de /o/ em Piranga

\begin{tabular}{|l|c|c|}
\hline \multicolumn{1}{|c|}{ Fator } & $\begin{array}{c}\text { Piranga } \\
\text { Alçamento de /o/ }\end{array}$ & $\begin{array}{c}\text { Piranga } \\
\text { Abertura de /o/ }\end{array}$ \\
\hline Vogal tônica & HV [-aberto2] & HV [+aberto3] \\
\hline Modo seguinte & [-soante +contínuo] & [-soante + contínuo] \\
\hline Classe gramatical & nome & \\
\hline Paradigma & & \\
\cline { 1 - 1 } Sexo & masculino/jovens & \\
\cline { 1 - 1 } Faixa etária & & \\
\cline { 3 - 3 } & &
\end{tabular}


QUADRO 5 - Fatores favorecedores da elevação de /ع/ e do alçamento de /e/ em Machacalis

\begin{tabular}{|l|c|c|}
\hline \multicolumn{1}{|c|}{ Fator } & $\begin{array}{c}\text { Machacalis } \\
\text { Elevação de } / \varepsilon /\end{array}$ & $\begin{array}{l}\text { Machacalis } \\
\text { alçamento de /e/ }\end{array}$ \\
\hline Vogal tônica & HV parcial [-aberto3] & HV total [-aberto2] \\
\hline Modo seguinte & [-silábico +soante] & [+nasal] \\
\hline Classe gramatical & & Verbos \\
\hline & & feminino/adulto \\
\cline { 1 - 1 } Sexo & & \\
\cline { 1 - 1 } Faixa etária & & \\
\cline { 1 - 2 }
\end{tabular}

QUADRO 6 - Fatores favorecedores da elevação de / $/$ / e do alçamento de /o/ em Machacalis

\begin{tabular}{|l|c|c|}
\hline \multicolumn{1}{|c|}{ Fator } & $\begin{array}{c}\text { Machacalis } \\
\text { Elevação de } / \mathrm{o} /\end{array}$ & $\begin{array}{c}\text { Machacalis } \\
\text { alçamento de /o/ }\end{array}$ \\
\hline Vogal tônica & HV parcial [-aberto3] & HV total [-aberto2] \\
\hline Modo seguinte & $\{$ [-silábico + soante] [-contínuo] $\}$ & [-soante + contínuo] \\
\hline Classe gramatical & & nomes \\
\hline Sexo & masculino & \\
\hline Faixa etária & & \\
\hline
\end{tabular}

Consideramos, neste trabalho, o efeito da vogal da sílaba tônica como o principal favorecedor dos processos envolvidos, pois, na hierarquização ${ }^{4}$ feita em Dias (2014), esse grupo de fator mostrou-se significativamente mais favorecedor aos processos que os demais grupos analisados.

Estamos analisando falares que realizam sete vogais em sua pauta pretônica e não apenas cinco (ver BISOL, 2013). Após as análises de (e) e (o), consideramos que em Ouro Branco e em Piranga temos as formas /e/ e /o/ como default para as vogais médias pretônicas, pois o número de contextos favorecedores da manutenção da vogal média alta é maior do que aqueles que favorecem os processos envolvidos.

\footnotetext{
${ }^{4}$ Baseando em Oliveira (2012), foi feito o teste da razão da máxima verossimilhança para hierarquizar as variáveis. Entre os fatores favorecedores, mediremos qual é mais atuante.
} 
A abertura da pretônica pode ocorrer quando a vogal da tônica é [ع], [०], [a], por um processo de harmonia vocálica do traço [+aberto3].

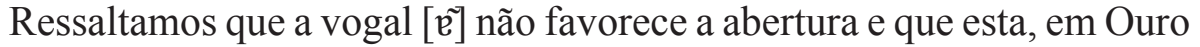
Branco, apresentou um percentual sempre muito inferior à manutenção.

Podemos dizer que o alçamento da pretônica ocorre nessas cidades por um processo de harmonia vocálica do traço [-aberto2].

Já em Machacalis, propomos que as vogais médias pretônicas default sejam $/ \varepsilon /$ e $/ \mathrm{o} /$, pois o número de contextos favorecedores do que seria caracterizado como abertura em outros falares é maior do que aqueles que favorecem a manutenção da vogal média alta e o alçamento.

Nessa cidade há vários contextos vocálicos favorecedores da abertura a mais do que as outras cidades - as vogais [ẽ], [õ] se apresentaram, na regressão, como favorecedoras, além das vogais [a], $[\varepsilon],[\circ]$. Em Machacalis não há restrição para a abertura provocada pela vogal da sílaba tônica, nas outras cidades quando a vogal da tônica é [e] ou [o] não há abertura.

Propomos que o processo para a realização [e] e [o], em Machacalis, seja de harmonia vocálica do traço [-aberto3], favorecido principalmente pelas vogais tônicas [e] e [o] seguintes e também pela vogal tônica seguinte

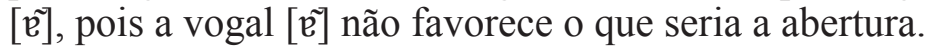

No alçamento da pretônica ocorre primeiro a harmonia parcial $/ \varepsilon, \mathrm{o} / \mathrm{e}, \mathrm{o} /$ (harmonia do traço [-aberto3]); e depois a harmonia total /e, o/ $\rightarrow$ /ou/ (harmonia do traço [-aberto2]), conforme Bisol (2013).

Qual seria a explicação para as distinções entre esses falares?

1) As vogais [ẽ], [õ] na sílaba tônica em Machacalis favorecem a forma média baixa da pretônica, pois temos [ẽ], [õ] mais baixas do que [e], [o], como explica Seara (2000).

Seara (2000) compara [e] e [ẽ] acusticamente e mostra que a frequência de $\mathrm{F} 1$ passa em média de $400 \mathrm{~Hz}$ (no segmento oral) para 502 $\mathrm{Hz}$ (no nasal). Então, [ẽ] é mais baixa do que [e], uma vez que quanto mais alto for F1, mais baixa é a vogal. A autora explica: "Enquanto para a vogal [a], a nasalidade torna a vogal menos baixa, a vogal [e], quando nasal, passa a menos alta, quer em contexto tônico quanto em átono" (SEARA, 2000, p. 77-78).

Sobre a posterior nasal, Seara afirma: "A vogal [õ] tem seu primeiro formante oral deslocado (F'1) elevando-se em freqüência, o que a torna menos alta do que sua correspondente não-nasal. Essa direção de 
deslocamento ocorre nos dois contextos de tonicidade analisados, sendo, no entanto, mais evidente em contexto tônico" (SEARA, 2000, p. 96).

Em Ouro Branco e em Piranga, provavelmente, o grau de dispersão dessas vogais em relação às vogais / $/ \varepsilon / \mathrm{e} / \mathrm{\jmath} /$ é maior do que em Machacalis, conforme Sândalo; Abaurre e Madruga (2013) a respeito do falar baiano.

2) Já a vogal [ヘீ] na sílaba tônica favorece a realização de [e], [o], pois [थ] é mais alta do que [a].

Seara compara [a] e [ã] acusticamente e mostra que " $O$ primeiro formante oral (F'1) da vogal nasal sofre um significativo abaixamento em frequência e enfraquece em intensidade, passando em média de 740 $\mathrm{Hz}$ (oral) para $560 \mathrm{~Hz}$ (nasal) em contexto tônico, e de $666 \mathrm{~Hz}$ (oral) para $597 \mathrm{~Hz}$ (nasal) em contexto átono" (SEARA, 2000, p. 62). Então, [ã] é mais alta do que [a], pois quanto mais baixo for F1, mais alta é a vogal.

A autora pontua ao se referir à vogal baixa central: "Verificamos assim [...] que a coloração nasal leva ao levantamento da vogal, isto é, a vogal nasal, tanto tônica quanto átona, é menos baixa do que a oral" (SEARA, 2000, p. 66).

O Instituto Camões apresenta um quadro que representa as vogais orais e nasais do português europeu (PE).

QUADRO 7 - Vogais orais e nasais do português europeu

\begin{tabular}{|c|c|c|c|}
\hline \multirow{2}{*}{ Altura } & \multicolumn{3}{|c|}{ Ponto de Articulação } \\
\cline { 2 - 4 } & Anterior ou Paleatal & Central & Posterior ou Velal \\
\hline \multirow{2}{*}{ Altas } & {$[\mathrm{i}, \tilde{\mathrm{i}}]$} & {$[\mathrm{t}]$} & {$[\mathrm{u}, \tilde{\mathrm{u}}]$} \\
\hline Médias & {$[\mathrm{e}, \tilde{\mathrm{e}}]$} & {$[\mathrm{e}, \tilde{\mathrm{e}}]$} & {$[\mathrm{o}, \tilde{\mathrm{o}}]$} \\
\hline Baixas & {$[\varepsilon]$} & {$[\mathrm{a}]$} & {$[\mathrm{0}]$} \\
\hline & Não Arredondadas & Arredondadas \\
\hline
\end{tabular}

Fonte: Instituto Camões, c2006.

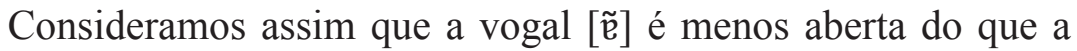
vogal [a] e por isso favorece a realização [e], [o] em Machacalis e em Piranga e Ouro Branco. 
3) A harmonia parcial $/ \varepsilon, \mathrm{o} / \rightarrow / \mathrm{e}, \mathrm{o} / \mathrm{e}$ a harmonia total $/ \mathrm{e}, \mathrm{o} / \rightarrow / \mathrm{i}, \mathrm{u} /$ são explicadas por Bisol (2013).

A autora explica que, no Sul/Sudeste, a neutralização anula a média aberta e no Norte/Nordeste ambas as médias emergem por assimilação.

Bisol cita alguns exemplos de variação tripartida em Teresina e ressalta que eles apontam para a harmonia gradual:

$$
\begin{aligned}
& \text { alcgria } \sim \text { alegria } \sim \text { aligria; } \\
& \text { fortuna } \sim \text { fortuna } \sim \text { furtuna } .
\end{aligned}
$$

\section{A autora explica:}

Segundo Trubetzkoy (1967, p.85), e-i formam uma oposição gradual somente em sistemas que possuem vogais com um grau de abertura maior do que e, separadas dessa vogal por um grau mínimo de abertura. Por conseguinte espera-se que harmonização gradual seja perceptível e captável em variedades do norte/ nordeste, em que ambas as médias estão presentes na forma de superfície, pois a média fechada separa-se da alta por um grau de abertura e a média aberta por dois graus. (BISOL, 2013, p. 55).

Bisol (2013) ressalta que a harmonia parcial é alimentadora da harmonia total, mas ela pode ou não prosseguir. Ou seja, pode ocorrer apenas a harmonia parcial $/ \varepsilon, \mathrm{o} / \rightarrow / \mathrm{e}, \mathrm{o} / \mathrm{e}$ aumentar o número de vogais médias ou ela pode prosseguir e ocorrer a harmonia total /e, o/ $\rightarrow / \mathrm{i}, \mathrm{u} /$. A autora pontua:

A primeira regra consiste em desligar o traço [ $+\mathrm{ab} 3]$ da média aberta, o alvo, para dar lugar ao traço [-ab3] da vogal alta vizinha, o gatilho, provocando a mudança de um grau de abertura, isto é, produzindo a média fechada, (alıgria $\rightarrow$ alegria). Como toda regra de mudança, desassocia-se um traço e introduz-se outro. A harmonização, como foi referido, pode parar neste ponto, aumentando o número das médias fechadas na pretônica. Todavia, pode prosseguir. A segunda regra desassocia o traço [+ab2] da vogal alvo para dar lugar a [-ab2] da vogal alta do gatilho, atingindo-se o efeito da harmonia total, por mudança de um grau de abertura. Em suma, a partir de al[ $\varepsilon$ ]gria realizam-se por gradação alegria e aligria. Isso ocorre tanto com a média [-post] quanto com a média [+post]. Portanto, a harmonia gradual é 
perceptível no português brasileiro em variedades que manifestam a média aberta no sistema pretônico. (BISOL, 2013, p. 57).

Segundo Bisol, em estudos anteriores, a média fechada diante de sílaba com vogal alta era tratada como exceção. Ela ressalta que "em variedades com sete vogais na pretônica, é, de fato, o efeito parcial da harmonia [...] pois, nesses sistemas, a média fechada, átona só emerge por assimilação, seja diante de média fechada, seja diante de vogal alta, esse com efeito parcial" (BISOL, 2013, p. 59).

\subsection{A Fonologia Autossegmental e a Geometria de Traços}

A partir das explicações anteriores, fazemos a proposição, para a $\operatorname{vogal} / \tilde{\mathrm{e}} /$, dos seguintes traços de abertura:

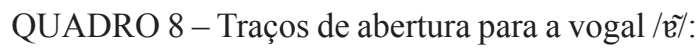

\begin{tabular}{|c|c|}
\hline Abertura / Vogal & $\tilde{\mathcal{B}^{-}}$ \\
\hline Aberto1 & + \\
\hline Aberto2 & + \\
\hline Aberto3 & - \\
\hline
\end{tabular}

Então, podemos propor a seguinte representação para os processos citados anteriormente em cada cidade:

\subsubsection{Ouro Branco e Piranga}

\subsubsection{Abertura}

\section{Representação da Harmonia vocálica do traço [+aberto3]}

$$
\begin{array}{ll}
{[\mathrm{e}, \mathrm{o}] \rightarrow[\varepsilon, 0} & \text { gatilho do processo: }[\varepsilon, \text { o }] \\
\mathrm{r}[\mathrm{e}] \mathrm{c}[\varepsilon] \mathrm{be} \rightarrow \mathrm{r}[\varepsilon] \mathrm{c}[\varepsilon] \mathrm{be} & \mathrm{n}[\mathrm{o}] \mathrm{v}[\varepsilon] \mathrm{la} \rightarrow \mathrm{n}[0] \mathrm{v}[\varepsilon] \mathrm{la} \\
\mathrm{n}[\mathrm{e}] \mathrm{g}[0] \mathrm{cio} \rightarrow \mathrm{n}[\varepsilon] \mathrm{g}[0] \mathrm{cio} & \mathrm{c}[\mathrm{o}] 1[\mathrm{o}] \mathrm{ca} \rightarrow \mathrm{c}[0] 1[0] \mathrm{ca}
\end{array}
$$




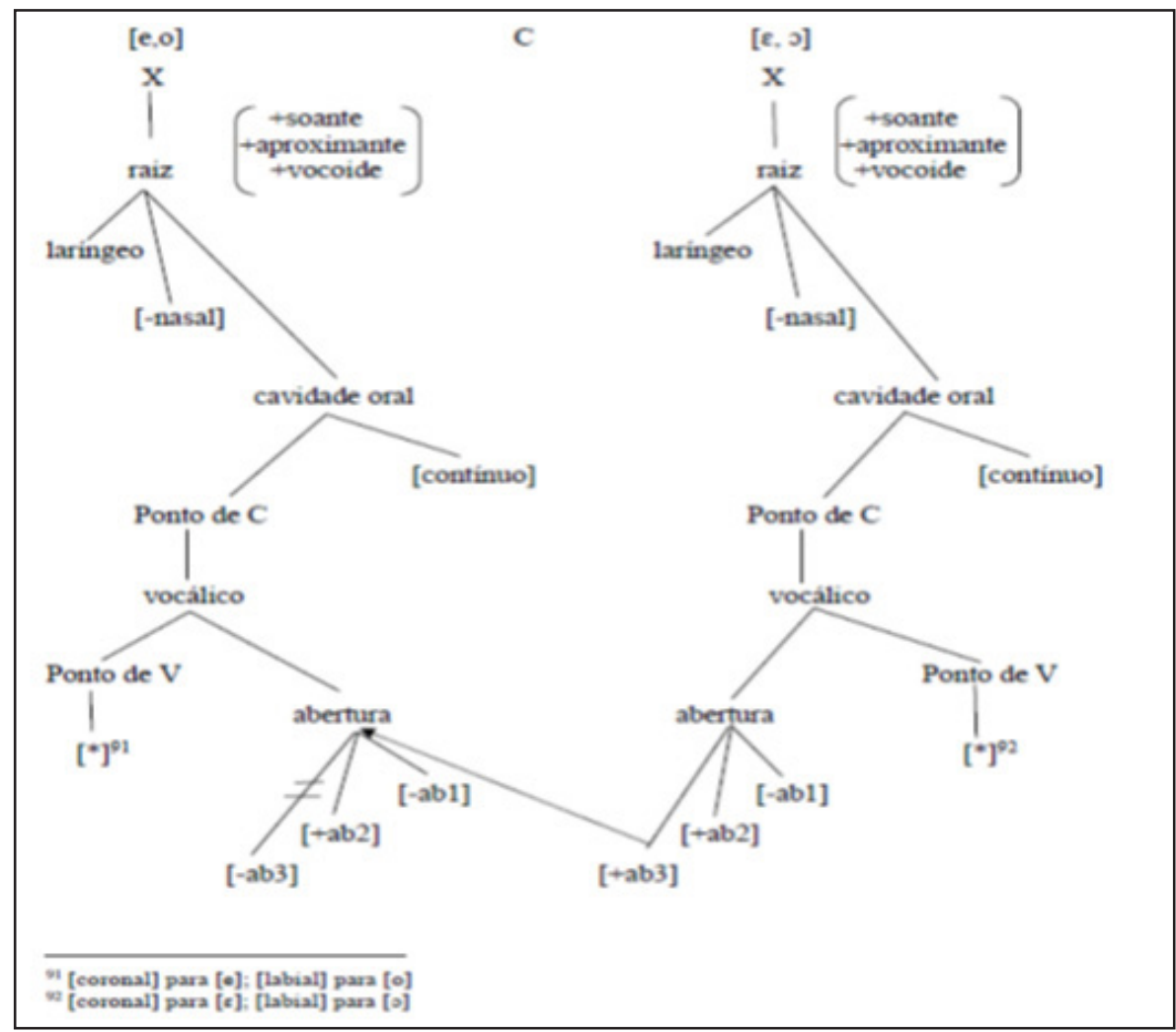

Fonte: Dias, 2014, p. 335.

O nó de abertura da vogal média alta tem seu traço [-aberto3] desligado para dar lugar ao traço [+aberto3] da vogal média baixa seguinte, que é o gatilho do processo. Assim, o nó de abertura da vogal média baixa espraia para o nó vocálico da vogal média alta, ocorrendo a mudança de um grau de abertura, ou seja, a vogal média pretônica [e, o], com traços [-ab1, +ab2, -ab3] assimila o traço [ + ab3] da vogal média baixa seguinte e torna-se média baixa também. Os traços [-ab1] e [+ab2] mantêm-se da mesma forma, já que são traços da vogal média baixa. Segundo Clements e Hume (1996), todos esses traços podem espraiar livremente através de consoantes simples, pois elas não têm nó vocálico para bloquear esse processo.

$$
\begin{array}{ll}
{[\mathrm{e}, \mathrm{o}] \rightarrow[\varepsilon, \mathrm{o}]} & \text { gatilho do processo: }[\mathrm{a}] \\
\mathrm{f}[\mathrm{e}] \text { chado } \rightarrow \mathrm{f}[\varepsilon] \text { chado } & \mathrm{g}[\mathrm{o}] \text { stava } \rightarrow \mathrm{g}[\mathrm{o}] \text { stava }
\end{array}
$$



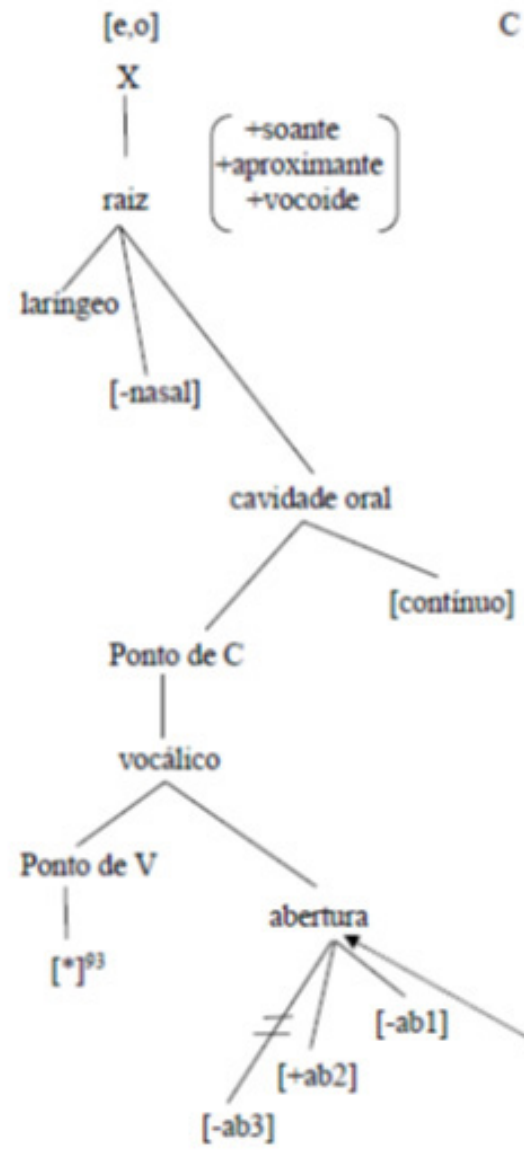

C

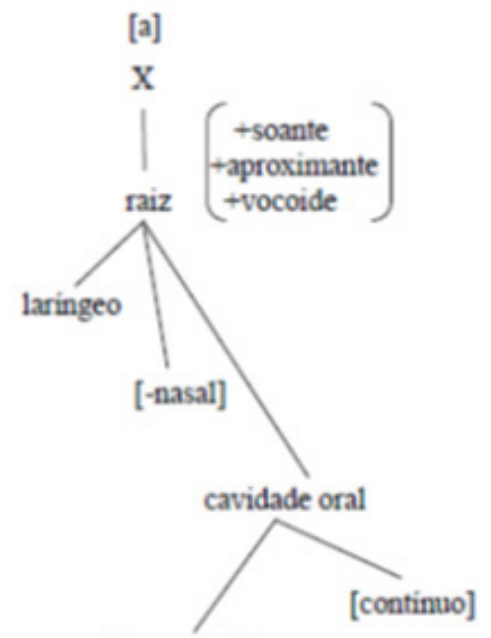

Ponto de C

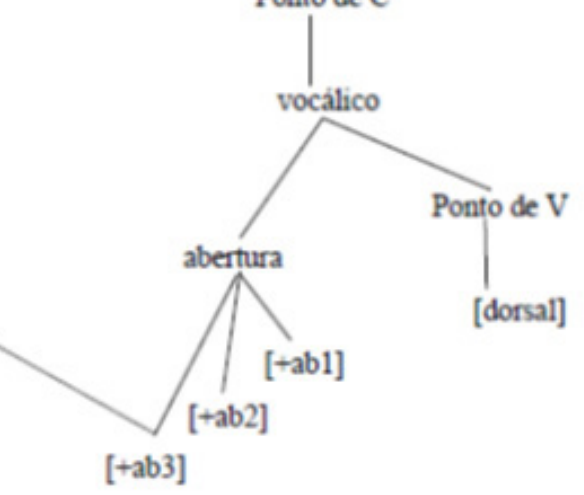

Fonte: Dias, 2014, p. 337.

O nó de abertura da vogal média alta tem seu traço [-aberto3] desligado para dar lugar ao traço [+aberto3] da vogal baixa seguinte, que é o gatilho do processo. Assim, o nó de abertura da vogal baixa seguinte espraia para o nó vocálico da vogal média alta, ocorrendo a mudança de um grau de abertura, ou seja, a vogal média pretônica [e, o], com traços [-ab1, +ab2, -ab3] assimila o traço [ + ab3] da vogal baixa seguinte e torna-se média baixa. Os traços[-ab1] e [+ab2] mantêm-se da mesma forma, já que são traços da vogal média baixa. Ressaltamos que a vogal média alta não assimila o traço [+ab1] da vogal baixa. 


\subsubsection{Alçamento - Representação da Harmonia vocálica do traço} [-aberto2]

$[\mathrm{e}, \mathrm{o}] \rightarrow[\mathrm{i}, \mathrm{u}]$

$\mathrm{b}[\mathrm{e}] \mathrm{b}[\mathrm{i}] \mathrm{da} \rightarrow \mathrm{b}[\mathrm{i}] \mathrm{b}[\mathrm{i}] \mathrm{da}$

$\mathrm{n}[\mathrm{e}] \mathrm{nh}[\mathrm{u}] \mathrm{m} \rightarrow \mathrm{n}[\mathrm{i}] \mathrm{nh}[\mathrm{u}] \mathrm{m} \mathrm{d}[\mathrm{o}] \mathrm{m}[\mathrm{i}] \mathrm{ngo} \rightarrow \mathrm{d}[\mathrm{u}] \mathrm{m}[\mathrm{i}]$ ngo
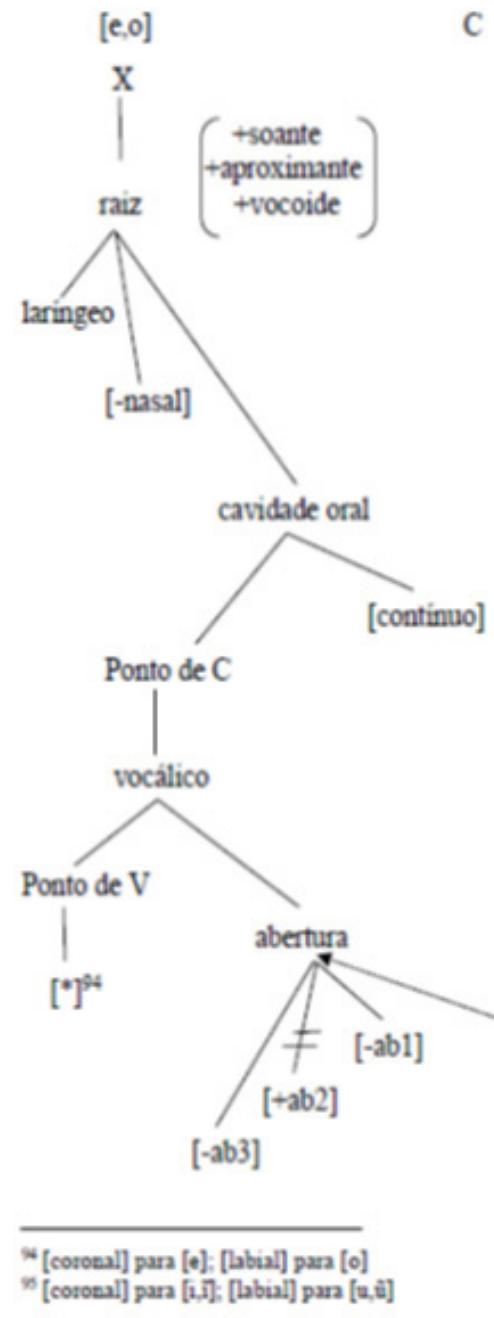

gatilho do processo: [i, u, î, ũ]

$\mathrm{g}[\mathrm{o}] \mathrm{rd}[\mathrm{u}] \mathrm{ra} \rightarrow \mathrm{g}[\mathrm{u}] \mathrm{rd}[\mathrm{u}] \mathrm{ra}$

C

$[i, u, \tilde{i}$, ũ] $]$

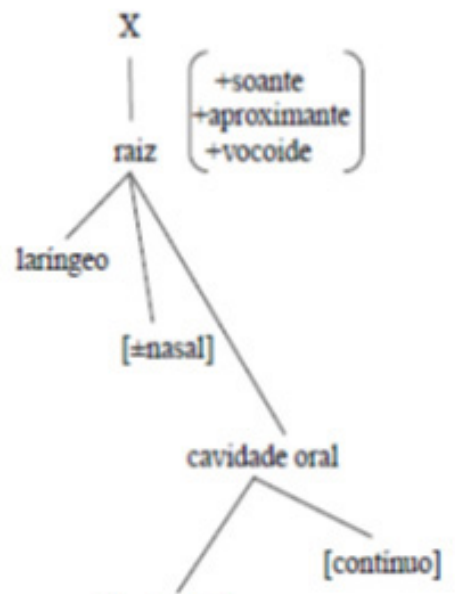

Ponto de C

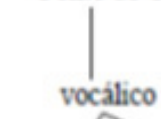


O nó de abertura da vogal média alta tem seu traço [+aberto2] desligado para dar lugar ao traço [-aberto2] da vogal alta seguinte, que é o gatilho do processo. Assim, o nó de abertura da vogal alta seguinte espraia para o nó vocálico da vogal média antecedente, ocorrendo a mudança de um grau de abertura, ou seja, a vogal média pretônica [e, o], com traços [-ab1, +ab2, -ab3], assimila o traço [-ab2] da vogal alta seguinte e torna-se alta também. Os traços [-ab1] e [-ab3] mantêm-se da mesma forma, já que são traços da vogal alta.

\subsubsection{Machacalis}

\subsubsection{Elevação de média baixa para média alta}

Representação da Harmonia vocálica do traço [-aberto3]

$[\varepsilon, \mathrm{o}] \rightarrow[\mathrm{e}, \mathrm{o}]$ gatilho do processo: $[\mathrm{e}, \mathrm{o}]$

$\mathrm{c}[\varepsilon] \mathrm{rt}[\mathrm{e}] \mathrm{za} \rightarrow \mathrm{c}[\mathrm{e}] \mathrm{rt}[\mathrm{e}] \mathrm{zac}[\mathrm{o}] \mathrm{rr}[\mathrm{e}] \mathrm{ios} \rightarrow \mathrm{c}[\mathrm{o}] \mathrm{rr}[\mathrm{e}]$ ios

$\mathrm{s}[\varepsilon] \mathrm{t}[\mathrm{o}] \mathrm{r} \rightarrow \mathrm{s}[\mathrm{e}] \mathrm{t}[\mathrm{o}] \mathrm{r} \quad \mathrm{f}[\mathrm{o}] \mathrm{rm}[\mathrm{o}] \mathrm{u} \rightarrow \mathrm{f}[\mathrm{o}] \mathrm{rm}[\mathrm{o}] \mathrm{u}$ 

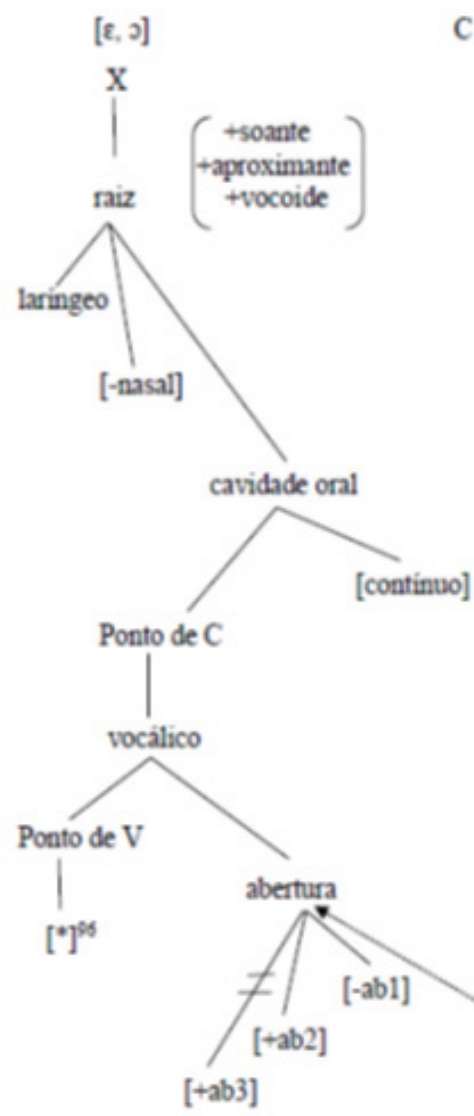

[+ab3]
C $[e, 0]$

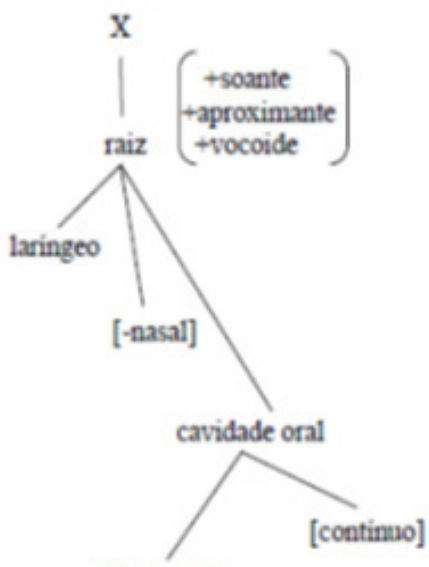

Ponto de C

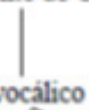

*[coronal] para [e]; [labial] para [0]

"[coronal] para [e]; [labial] para [0]

Fonte: Dias, 2014, p. 340.

O nó de abertura da vogal média baixa tem seu traço [+aberto3] desligado para dar lugar ao traço[-aberto3] da vogal média alta seguinte, que é o gatilho do processo. Assim, o nó de abertura da vogal média alta seguinte espraia para o nó vocálico da vogal média baixa, ocorrendo a mudança de um grau de abertura, ou seja, a vogal média pretônica [ $\varepsilon$, o], com traços[-ab1, +ab2, +ab3] assimila o traço [-ab3] da vogal média alta seguinte e torna-se média alta também. Os traços [-ab1] e [+ab2] mantêm-se da mesma forma, já que são traços da vogal média alta. 
$[\varepsilon$, o] $\rightarrow[\mathrm{e}, \mathrm{o}]$ gatilho do processo: [r]

$\mathrm{ch}[\varepsilon]$ gando $\rightarrow \mathrm{ch}[\mathrm{e}]$ gando $\quad \mathrm{v}[\mathrm{o}]$ lante $\rightarrow \mathrm{v}[\mathrm{o}]$ lante

$[\varepsilon$, J]

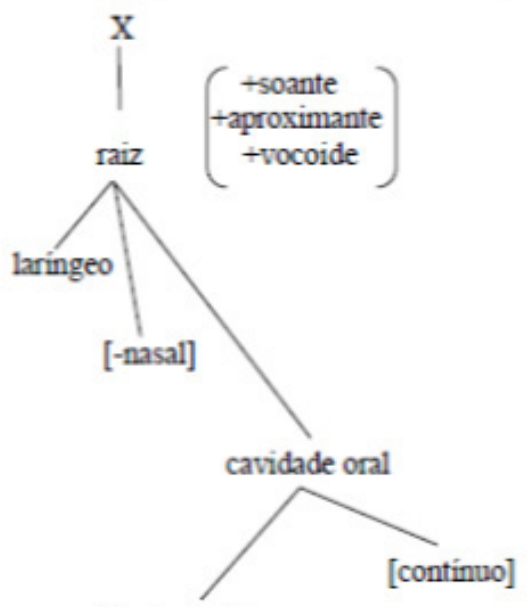

Ponto de C

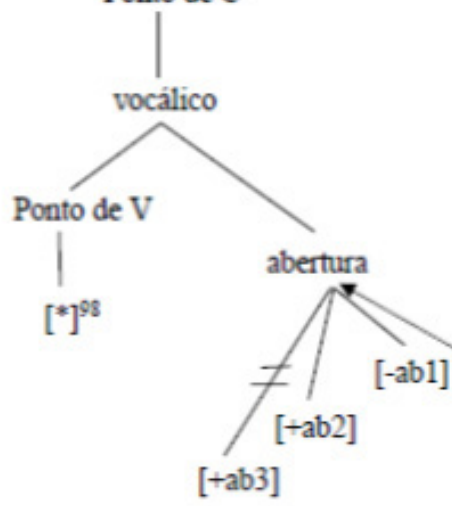

C

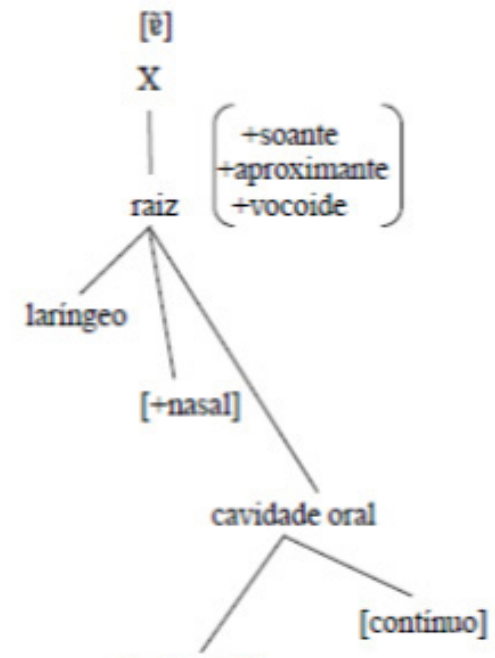

Ponto de C

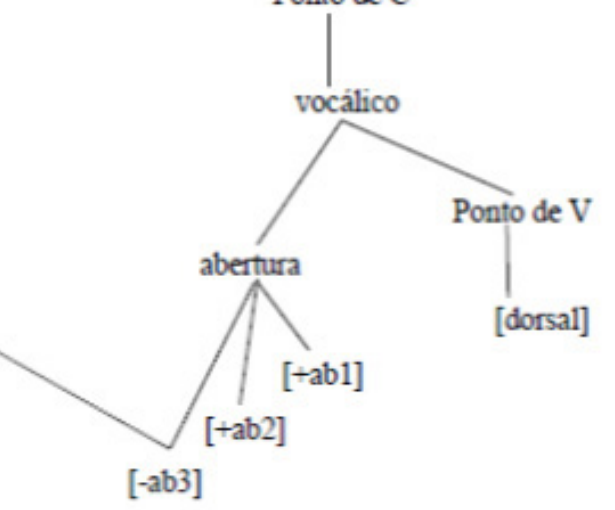

"[coronal] para [r]; [bbial] para [?]

Fonte: DIAS, 2014, p. 341. 
O nó de abertura da vogal média baixa tem seu traço [+aberto3] desligado para dar lugar ao traço[-aberto3] da vogal baixa nasal seguinte, que é o gatilho do processo. Assim, o nó de abertura da vogal baixa nasal seguinte espraia para o nó vocálico da vogal média baixa, ocorrendo a mudança de um grau de abertura, ou seja, a vogal média pretônica $[\varepsilon, 0]$, com traços[-ab1, +ab2, +ab3] assimila o traço [-ab3] da vogal baixa nasal seguinte e torna-se média alta. Os traços [-ab1] e [+ab2] mantêm-se da mesma forma, já que são traços da vogal média alta. Ressaltamos que a vogal média baixa não assimila o traço [+ab1] da vogal baixa nasal.

\subsubsection{Alçamento}

Como em Machacalis propusemos / $\varepsilon /$, / / / como default, então para ocorrer a harmonia total é preciso que antes ocorra a parcial. Bisol (2013) explica:

A harmonização que atinge as médias abertas $/ \varepsilon, \mathrm{o} /$ com o efeito parcial tem a peculiaridade de funcionar como alimentadora da harmonia total /e,o/ $\rightarrow$ /i, u/, embora disponha da liberdade de não prosseguir, aumentando o número de médias no sistema, assim como tem a liberdade de partir também de outros /e, o/ préexistentes. (BISOL, 2013, p. 56).

\section{Representação da Harmonia Parcial - harmonia vocálica do traço [-aberto3]}

$$
\begin{aligned}
& {[\varepsilon, \mathrm{o}] \rightarrow[\mathrm{e}, \mathrm{o}] \text { gatilho do processo: }[\mathrm{i}, \mathrm{u}, \tilde{\mathrm{i}}, \tilde{\mathrm{u}}]} \\
& \mathrm{s}[\varepsilon] \mathrm{gu}[\mathrm{i}] \text { nte } \rightarrow \mathrm{s}[\mathrm{e}] \mathrm{gu}[\mathrm{i}] \text { nte } \quad \mathrm{c}[\mathrm{o}] \mathrm{m}[\mathrm{i}] \mathrm{da} \rightarrow \mathrm{c}[\mathrm{o}] \mathrm{m}[\mathrm{i}] \mathrm{da} \\
& \mathrm{s}[\varepsilon] \mathrm{g}[\mathrm{u}] \mathrm{ro} \rightarrow \mathrm{s}[\mathrm{e}] \mathrm{g}[\mathrm{u}] \mathrm{ro} \quad \mathrm{c}[\mathrm{o}] \mathrm{st}[\mathrm{u}] \mathrm{me} \rightarrow \mathrm{c}[\mathrm{o}] \mathrm{st}[\mathrm{u}] \mathrm{me}
\end{aligned}
$$




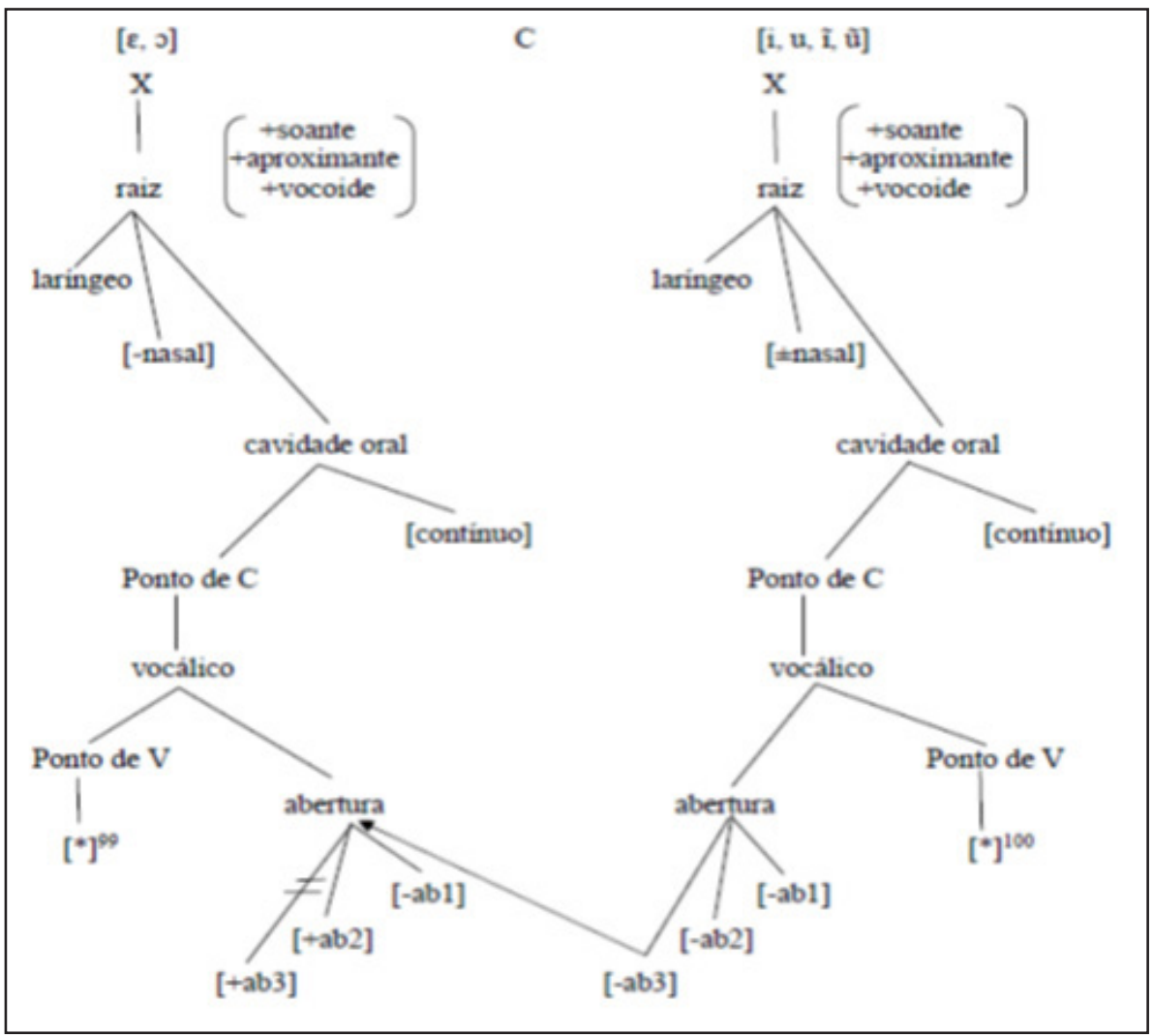

Fonte: Dias, 2014, p. 343.

O nó de abertura da vogal média baixa tem seu traço [+aberto3] desligado para dar lugar ao traço [-aberto3] da vogal alta seguinte, que é o gatilho do processo. Assim, o nó de abertura da vogal alta seguinte espraia para o nó vocálico da vogal média baixa antecedente, ocorrendo a mudança de um grau de abertura, ou seja, a vogal média pretônica $[\varepsilon$, o], com traços [-ab1, +ab2, +ab3] assimila o traço [-ab3] da vogal alta seguinte e torna-se média alta, ocorrendo a harmonia parcial.

Como Bisol (2013) explica, a harmonia pode parar aqui e aumentar o número de vogais médias ou ela pode prosseguir e ocorrer a harmonia total /e, o/ $\rightarrow$ /ou/, representada a seguir: 


\section{Representação da Harmonia Total -harmonia vocálica do traço [-aberto2]}

$[\mathrm{e}, \mathrm{o}] \rightarrow[\mathrm{i}, \mathrm{u}]$ gatilho do processo: $[\mathrm{i}, \mathrm{u}, \tilde{\mathrm{i}}, \tilde{\mathrm{u}}]$

$\mathrm{s}[\mathrm{e}] \mathrm{gu}[\mathrm{i}] \mathrm{nte} \rightarrow \mathrm{s}[\mathrm{i}] \mathrm{gu}[\mathrm{i}] \mathrm{nte} \quad \mathrm{c}[\mathrm{o}] \mathrm{m}[\mathrm{i}] \mathrm{da} \rightarrow \mathrm{c}[\mathrm{u}] \mathrm{m}[\mathrm{i}] \mathrm{da}$

$\mathrm{s}[\mathrm{e}] \mathrm{g}[\mathrm{u}] \mathrm{ro} \rightarrow \mathrm{s}[\mathrm{i}] \mathrm{g}[\mathrm{u}] \mathrm{ro} \quad \mathrm{c}[\mathrm{o}] \mathrm{st}[\mathrm{u}] \mathrm{me} \rightarrow \mathrm{c}[\mathrm{u}] \mathrm{st}[\mathrm{u}] \mathrm{me}$

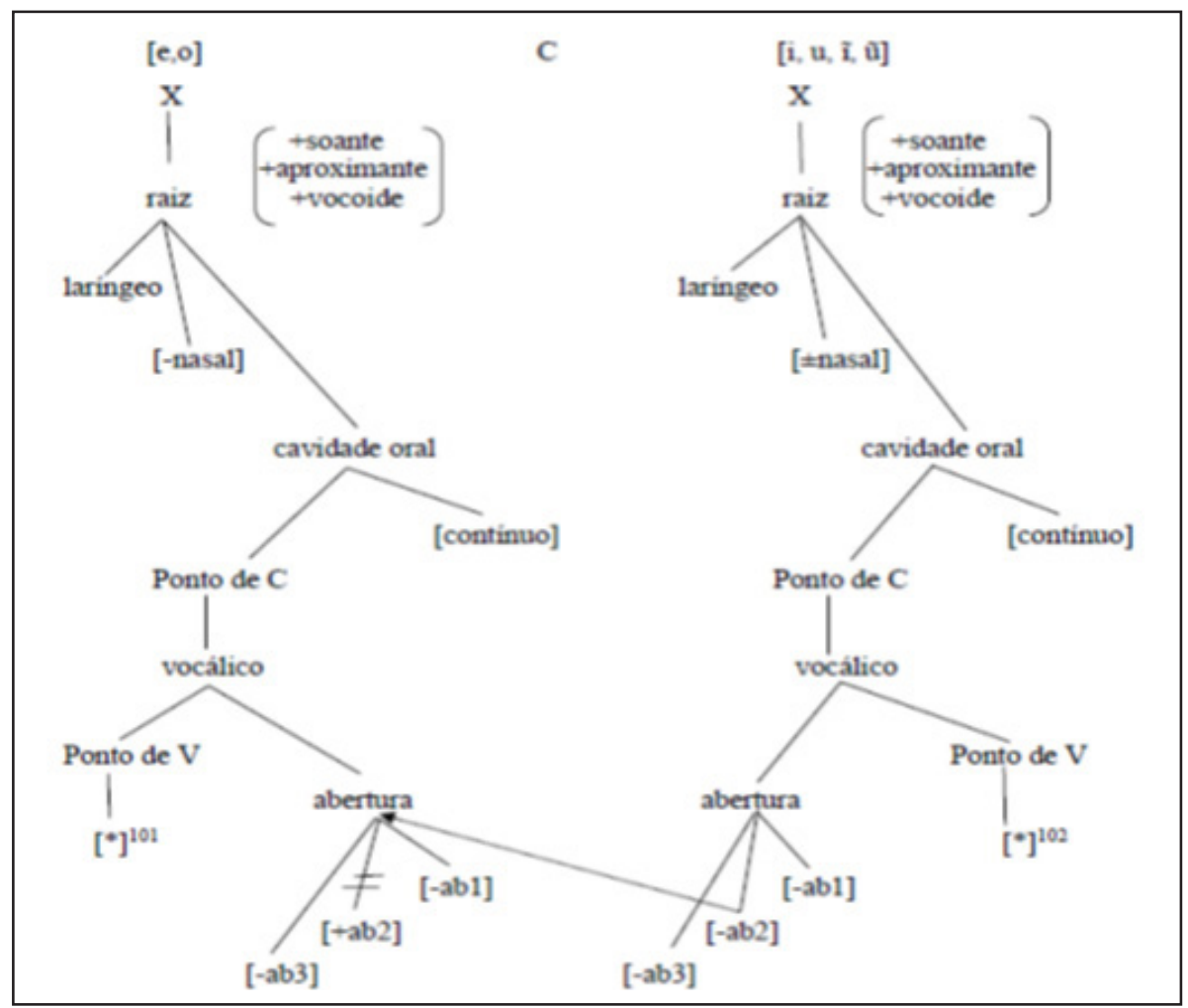

Fonte: Dias, 2014, p. 345.

O nó de abertura da vogal média alta tem seu traço [+aberto2] desligado para dar lugar ao traço [-aberto2] da vogal alta seguinte, que é o gatilho do processo. Assim, o nó de abertura da vogal alta seguinte espraia para o nó vocálico da vogal média antecedente, ocorrendo a mudança de um grau de abertura, ou seja, a vogal média pretônica [e, o], com traços [-ab1, +ab2, -ab3] assimila o traço [-ab2] da vogal alta seguinte e tornase alta também. Os traços [-ab1] e [-ab3] mantêm-se da mesma forma, já que são traços da vogal alta. 


\section{Comparação entre os falares}

Machacalis pertence ao falar baiano. Portanto, considerando a divisão de Nascentes (1953) e os resultados obtidos durante a nossa pesquisa, podemos propor para essa cidade as vogais $/ \varepsilon /$ e $/ \mathrm{J} /$ como default. As observações de Mota (1979), Cardoso (1986), Callou; Leite e Coutinho (1991) e Bisol (2013), apresentadas a seguir, corroboram nossa proposta.

Mota explica:

[...] os dialetos diferem também quanto à estrutura subjacente e não apenas quanto às regras fonológicas que a relacionam à estrutura superficial. As próprias falhas na imitação de dialetos por falantes de outras áreas podem ser vistas, segundo HAUSMANN, como indício de que os diversos dialetos de uma língua apresentam diferentes estruturas subjacentes, ao contrário do que até então propunha a Fonologia Gerativa Transformacional. (MOTA, 1979, p. 20).

Cardoso (1986), ao examinar a divisão dialetal do Brasil proposta por Nascentes, à luz dos dados fornecidos pelo Atlas prévio dos falares baianos e pelo Esboço de um atlas linguístico de Minas Gerais, explica, ao se referir ao falar baiano, que a maior frequência foi das vogais médias abertas, tanto anteriores quanto posteriores.

Acresce a isso o fato de as ocorrências de [e] e [o] distribuíremse de forma generalizada pelo território baiano o que demonstra a inexistência de área ou áreas específicas. A distribuição das ocorrências de $[\mathrm{e}] \mathrm{e}$ [o] permite-nos concluir que a presença das vogais médias fechadas em posição pretônica não se define como traço característico de região, mas configura-se como uma variante livre de $[\varepsilon]$ e [o], que se afiguram como realizações básicas na área. (CARDOSO, 1986, p. 50).

Callou; Leite e Coutinho pontuam:

Para finalizar, gostaríamos de assinalar que é extremamente difícil com os dados disponíveis decidir se alteamento e abaixamento constituem inovação ou conservação. Falou-se até aqui em regra de abaixamento, partindo-se do pressuposto de que a forma básica histórica é /e/, a harmonização sendo de alteamento $\mathrm{e} \rightarrow \mathrm{i}$ e a ocorrência de vogais baixas indicando uma simplificação da 
regra, isto é, uma inovação. Outra interpretação possível, calcada também em dados históricos e corroborada pelo fato de ter sido anotada de preferência em pessoas mais velhas, seria interpretar a ocorrência de vogais baixas como uma manutenção, o processo histórico sendo $\varepsilon \rightarrow \mathrm{e} \rightarrow \mathrm{i}$. (CALLOU; LEITE; COUTINHO, 1991, p. 77).

Bisol, ao comparar os efeitos da harmonização vocálica em duas variedades do PB (Sul/Sudeste e Norte/Nordeste), mostra que no Norte/ Nordeste a vogal que entra como default é a média aberta: "Quando não há contexto para assimilação ou quando a assimilação que produz as médias deixa de atuar por ser regra variável, entra como default, no sentido de vogal de maior uso, a média aberta" (BISOL, 2013, p. 57).

Assim, podemos propor os seguintes processos fonéticofonológicos em cada cidade:

QUADRO 9 - Processos fonético-fonológicos e m Ouro Branco, Piranga e Machacalis

\begin{tabular}{|c|c|c|}
\hline Ouro Branco & Piranga & Machacalis \\
\hline /e/ /o/ & /e/ /o/ & $/ \varepsilon / / 0 /$ \\
\hline $\mathrm{HV}^{5}$ do traço [+aberto3] & HV do traço [+aberto3] & HV do traço [-aberto3] \\
\hline HV do traço [-aberto2] & HV do traço [-aberto2] & HV parcial [-aberto3] e HV total [-aberto2] \\
\hline
\end{tabular}

Em Machacalis, a harmonia parcial [-aberto3] é igual à elevação de média baixa para média alta (HV do traço [-aberto3]). Podemos observar nas representações que fizemos anteriormente que a diferença é apenas o gatilho do processo. Para a elevação, temos como gatilho

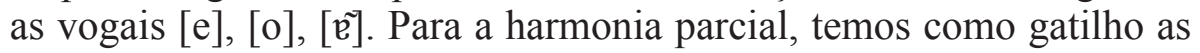
vogais altas. Mas o processo é o mesmo, assimilação do traço [-aberto3].

\section{Considerações Finais}

Resumindo os processos apresentados, temos apenas dois processos para cada cidade:

${ }^{5} \mathrm{HV}=$ Harmonia Vocálica 
1) HV do traço [+aberto3] - Ouro Branco e Piranga

2) HV do traço [-aberto3] - Machacalis

3) HV do traço [-aberto2] - Ouro Branco, Piranga e Machacalis

Portanto, Machacalis se mostra claramente diferente das outras cidades. Já Ouro Branco e Piranga apresentam os mesmos defaults e os mesmos processos, mas ressaltamos que há diferenças percentuais entre essas cidades. Vejamos os percentuais de manutenção e abertura nessas cidades quando a vogal da tônica é favorecedora da abertura ([ع], [0], [a]):

TABELA 2 - Percentuais de manutenção e abertura para /e/, com vogal tônica [c], [0], [a], em Ouro Branco e Piranga

\begin{tabular}{|c|c|c|c|c|c|}
\hline \multirow{2}{*}{\multicolumn{2}{|c|}{ Variantes }} & \multicolumn{2}{|c|}{$\begin{array}{l}\text { Ouro Branco } \\
\text { v. tônica }\end{array}$} & \multicolumn{2}{|c|}{$\begin{array}{l}\text { Piranga } \\
\text { v. tônica }\end{array}$} \\
\hline & & [a] & {$[\varepsilon],[0]$} & [a] & {$[\varepsilon],[\supset]$} \\
\hline [e] & $\begin{array}{l}\mathrm{n} \\
\%\end{array}$ & $\begin{array}{c}83 \\
86,5 \%\end{array}$ & $\begin{array}{c}74 \\
85,1 \%\end{array}$ & $\begin{array}{c}33 \\
27,5 \%\end{array}$ & $\begin{array}{c}12 \\
28,6 \%\end{array}$ \\
\hline$[\varepsilon]$ & $\begin{array}{l}\mathrm{n} \\
\%\end{array}$ & $\begin{array}{c}13 \\
13,5 \%\end{array}$ & $\begin{array}{c}13 \\
14,9 \%\end{array}$ & $\begin{array}{c}87 \\
72,5 \%\end{array}$ & $\begin{array}{c}30 \\
71,4 \%\end{array}$ \\
\hline Total & $\begin{array}{l}\text { n } \\
\%\end{array}$ & $\begin{array}{c}96 \\
100,0 \%\end{array}$ & $\begin{array}{c}87 \\
100,0 \%\end{array}$ & $\begin{array}{c}120 \\
100,0 \%\end{array}$ & $\begin{array}{c}42 \\
100,0 \%\end{array}$ \\
\hline
\end{tabular}

TABELA 3 - Percentuais de manutenção e abertura para /o/, com vogal tônica [c], [0], [a], em Ouro Branco e Piranga

\begin{tabular}{|c|c|c|c|c|c|}
\hline \multicolumn{2}{|c|}{ Variantes } & \multicolumn{2}{|c|}{$\begin{array}{c}\text { Ouro Branco } \\
\text { v. tônica }\end{array}$} & \multicolumn{2}{|c|}{$\begin{array}{l}\text { Piranga } \\
\text { v. tônica }\end{array}$} \\
\hline & & [a] & {$[\varepsilon],[\mathfrak{~}]$} & [a] & {$[\varepsilon],[0]$} \\
\hline [o] & $\begin{array}{c}\mathrm{n} \\
\%\end{array}$ & $\begin{array}{c}55 \\
67,1 \%\end{array}$ & $\begin{array}{c}44 \\
77,2 \%\end{array}$ & $\begin{array}{c}11 \\
13,4 \%\end{array}$ & $\begin{array}{c}5 \\
13,2 \%\end{array}$ \\
\hline [0] & $\begin{array}{c}\mathrm{n} \\
\%\end{array}$ & $\begin{array}{c}27 \\
32,9 \%\end{array}$ & $\begin{array}{c}13 \\
22,8 \%\end{array}$ & $\begin{array}{c}71 \\
86,6 \%\end{array}$ & $\begin{array}{c}33 \\
86,8 \%\end{array}$ \\
\hline Total & $\begin{array}{l}\mathbf{n} \\
\%\end{array}$ & $\begin{array}{c}82 \\
100,0 \%\end{array}$ & $\begin{array}{c}57 \\
100,0 \%\end{array}$ & $\begin{array}{c}82 \\
100,0 \%\end{array}$ & $\begin{array}{c}38 \\
100,0 \%\end{array}$ \\
\hline
\end{tabular}

Os percentuais de abertura em Ouro Branco e Piranga são muito diferentes. Em Ouro Branco prevalece a manutenção, mesmo com vogal tônica favorecedora da abertura. Já em Piranga, o percentual de abertura nesse contexto é muito alto. 
Além desses processos, os resultados das regressões mostraram que há também atuação das consoantes seguintes tanto para a abertura quanto para o alçamento. Ressaltamos que os processos resultantes da influência das consoantes não foram analisados de acordo com a Teoria Autossegmental devido à necessidade de refinamento da análise, pois não pesquisamos cada consoante detalhadamente, o que nos impossibilita fazer a representação.

Há ainda outros grupos de fatores operando, por exemplo, o paradigma com vogal aberta e o acento secundário, que não foram analisados detalhadamente neste texto.

Além desses, é importante ressaltar que há questões lexicais atuando. Para a grande parte dos dados, podemos postular processos fonético-fonológicos, mas ressaltamos que, tanto para (e) quanto para (o), para o alçamento e para a abertura, observamos a atuação de itens lexicais, principalmente nos casos em que, no mesmo contexto, um item sempre alça e o outro nunca alça. Esses aspectos foram considerados no texto de Lemos e Viegas (2016).

Esses grupos de fatores ou foram controlados na análise dos dados ou foram inseridos na regressão, validando assim os resultados encontrados.

Se levarmos em consideração apenas os processos fonéticofonológicos, poderíamos dizer que a divisão dos falares de Minas apresentada em Zágari (1998) seria a divisão mais interessante. Nessa divisão, o falar de Piranga estaria na mesma área de Ouro Branco, pois os processos em nesses municípios são os mesmos. Assim, Piranga e Ouro Branco pertenceriam à área de falar mineiro e Machacalis à área de falar baiano.

Cremos, assim, ter respondido as perguntas inicialmente propostas.

\section{Referências}

BISOL, L. Harmonização vocálica: efeito parcial e total. Organon, Revista do Instituto de Letras da UFRS, Porto Alegre, v. 28, n. 54, p. 4961, jan./jun. 2013.

CALLOU, D.; LEITE, Y.; COUTINHO, L. Elevação e abaixamento das vogais pretônicas no dialeto do Rio de Janeiro. Organon, Revista do Instituto de Letras da UFRS, Porto Alegre, v. 5, n. 18, p. 71-78, 1991. 
CARDOSO, S. A. M. Tinha Nascentes razão? Estudos Linguísticos e Literários, Revista do Programa de Pós-Graduação em Letras e Linguística da UFBa, Salvador, n. 5, p. 47-59, 1986.

CLEMENTS, G. N.; HUME, E. The Internal Organization of Speech Sounds. In: GOLDSMITH, J. (Org.). The Handbook of Phonological Theory. London: Blackwell Publishing, 2007, p. 1-47. Disponível em: $<$ https://pt.scribd.com/document/209272940/Clement-e-Hume-1995The-Internal-Organization-of-Speech-Sounds\#>. Acesso em: 17 out. 2017.

DIAS, M. R. Estudo comparativo da variação das vogais médias pretônicas em falares mineiros. 2014. 372 f. Tese (Doutorado em Estudos Linguísticos) - Faculdade de Letras, Universidade Federal de Minas Gerais, Belo Horizonte, 2014.

GOLDSMITH, J. A. Autosegmental Phonology. 1976. 280 f. Tese (Doutorado) -Massachusetts Institute of Technology, Cambridge, Mass., 1976.

INSTITUTO CAMÕES. Fonética e fonologia: que diferença? c2006 Disponível em: <http://cvc.instituto-camoes.pt/cpp/acessibilidade/ capitulo3_1.html>. Acesso em: 15 abr. 2014.

LABOV, W. Sociolinguistic Patterns. Philadelphia: University of Pennsylvania Press, 1972.

LEMOS, F. A. P.; VIEGAS, M. C. O alçamento das vogais médias pretônicas em falares mineiros: os dados. Caletroscópio, Revista do Programa de Pós-Graduação em Letras: Estudos da Linguagem da UFOP, Ouro Preto, v. 4, p. 314-323, 2016. Número especial.

MATZENAUER, C. L. B. Introdução à teoria fonológica. In: BISOL, L. (Org.). Introdução a estudos de fonologia do português. 5. ed. rev. Porto Alegre: EDIPUCRS, 2010.

MOTA, J. A. Vogais antes de acento em Ribeirópolis - SE. 1979. 290 f. Dissertação (Mestrado em Língua Portuguesa)-Universidade Federal da Bahia, Salvador, 1979. 2v.

NASCENTES, A. O linguajar carioca. Rio de Janeiro: Simões, 1953. 
OLIVEIRA, A. J. de. Comendo o final das palavras: análise variacionista da haplologia, elisão e apócope em Itaúna/MG. 2012. 296 f. Tese (Doutorado em Estudos Linguísticos) - Faculdade de Letras, Universidade Federal de Minas Gerais, Belo Horizonte, 2012.

SÂNDALO, F.; ABAURRE, M. B. M.; MADRUGA, M. R. Dispersão e harmonia vocálica em dialetos do português do Brasil. Organon, Revista do Instituto de Letras da UFRS, Porto Alegre, v. 28, n. 54, p.13-30, jan./ jun. 2013.

SEARA, I. C. Estudo acústico-perceptual da nasalidade das vogais do Português Brasileiro. 2000. 270 f. Tese (Doutorado em Linguística) Departamento de Língua e Literatura Vernáculas, Universidade Federal de Santa Catarina, Florianópolis, 2000.

ZÁGARI, M. R. L. Os falares mineiros: esboço de um atlas linguístico de Minas Gerais. In: AGUILERA, V. de A. (Org.). A Geolinguística no Brasil - caminhos e perspectivas. Londrina: Editora da Universidade Estadual de Londrina, 1998. p. 31-54. 